\title{
Mango Butter: a Low-Cost Structuring Material for Food Applications
}

\author{
Dilshad Qureshi ${ }^{1}$, Suraj Kumar Nayak ${ }^{1}$, Doman Kim²*and Kunal Pal ${ }^{1 *}$ \\ ${ }^{1}$ Department of Biotechnology and Medical Engineering, National Institute of Technology, Rourkela, India \\ ${ }^{2}$ Department of International Agricultural Technology \& Institute of Green Bioscience and Technology, Seoul National University, Republic of Korea
}

Submission: October 16, 2017; Published: January 08, 2018

*Corresponding author: Doman Kim, Department of International Agricultural Technology \& Institute of Green Bioscience and Technology, Seoul National University, Gwangwon-do-25354, Republic of Korea, Email: kimdm@snu.ac.kr

Kunal Pal, Department of Biotechnology and Medical Engineering, National Institute of Technology, Rourkela- 769008, India, Email: kpal.nitrkl@gmail.com

\begin{abstract}
Mango is the most common tropical fruit available worldwide. Its each part contains a pool of nutrients, e.g., vitamins, carbohydrates, antioxidants, protein, fats and phenolic compounds. Unfortunately, besides pulp, its kernels and peels are discarded by the fruit processing industries without utilizing their full potential. The fat extracted from the mango seed kernel (MSK) is regarded as mango butter or mango kernel oil. It has gained widespread applications in non-food industries like cosmetics, and pharmaceutical. In food industry, mango butter has shown great promise to serve different roles such as natural antioxidant, trans-fat free edible oil, food additive, functional food ingredient, cocoa butter equivalent in chocolate and confectionaries. This article attempts to highlight the physicochemical properties and recently proposed food applications of mango butter.
\end{abstract}

Keywords: Mango; Mango butter; Bioactive compound; Physicochemical property; Food applications

\section{Introduction}

Mango is an important tropical fruit, usually found in Southern Asia and Central America [1]. It belongs to the genus Mangifera, which comprises of about 30 species of fruiting plants. It is categorized under the flowering plant family Anacardiaceae [2]. The mango fruit is regarded as the king of fruits due to its pleasant taste, eye catching color and chemical composition [3-4]. It is ranked as the second most traded and fifth most cultivated tropical fruit in the world [3].

Its structure consists of: (i) a pericarp or peel (either thick or thin) with a great degree of color variation from green to orange, (ii) an edible, juicy, and fibrous mesocarp (pulp) with varying texture, thickness, color and taste at different stages of development, and (iii) a stony, kidney or bean-shaped endocarp (pit) incorporating a kernel inside it [5]. The weight percent contributed by the seed to the total fruit weight is $10 \%-25 \%$ and the kernel comprises of $45 \%$ to $85 \%$ of the seed depending on the variety of the mango [3]. The mango seed kernel (MSK) has been reported to contain bioactive compounds (e.g., carotenoids, dietary fiber, vitamin $\mathrm{C}$ and phenolic compounds), micronutrients (like $\mathrm{Ca}, \mathrm{Mg}, \mathrm{P}, \mathrm{K}$, $\mathrm{Na}$, etc.), carbohydrates, proteins, and fats [3]. Mango butter, i.e., the fat content of the MSK, is pale yellow in color (due to the low concentration of carotenoids) [4] with a semi-solid consistency, and mild fragrance at room temperature, but melts at body temperature. It has found wide applications in drug delivery, cosmetics and food industry [6]. This article describes the properties and importance of mango butter as a low-cost structuring material in food industry.

\section{Physicochemical Properties of Mango Butter}

On the account of the continuous increase in the human population size, there is an acute shortage of the edible oils [7]. Consequently, there is a need to explore the plant sources for the production of the cheap edible oil supply with qualities and composition similar or better than the conventional ones. The underutilized mango kernels are discarded as the waste by the people and the fruit processing industries, creating enormous waste production. However, the scientists have evinced the nutritional importance of this mango waste in the last few decades [4]. The mango butter has been reported to be fit for human consumption without any adverse effects on the body akin to other solid edible fats [8]. It contain $45 \%$ unsaturated oleic acid (C18:1) and 38\% saturated stearic (C18:0) acid as the predominant fatty acids [9]. The remaining fats include linoleic acid, palmitic acid, and triglycerides (e.g., 1,3-distearoyl-2-oleoyl-glycerol (SOS) and 1-palmitoyl2-oleoyl-3-stearoyl-glycerol (POS)) [6]. Numerous scientific studies have highlighted the antioxidant properties due to 
the phenolic content and the free radical scavenging activity of mango butter [4]. Many studies have been conducted to evaluate the physicochemical properties of mango butter in order to explore its suitability for different applications [4]. The method of extraction has been found to influence the physicochemical properties of the mango butter [9].

\section{Food Applications of Mango Butter}

Many studies have been performed to explore the suitability of mango butter for different applications in the food industry. The shortage of edible oils (especially in the developing countries) has motivated the researchers to search for new untraditional sources of edible oils. In the last few decades, plenty of research has been carried out to explore the potential of mango butter as an edible oil having high antioxidative and antimicrobial nature [10]. Abdel-Razik et al. [11] reported that the characteristics of mango butter are in the normal range of the edible oils, and hence, it can be a potential candidate as an edible oil [11]. The auto-oxidation of oils and fats results in the formation of toxic oxidation products. On the other hand, the commonly used synthetic antioxidants are carcinogenic [12]. Jafari et al. [13] reported the use of mango butter as a natural antioxidant concentrate [13]. 1\%, 5\% and $10 \%$ concentrations of mango butter were blended with tallow. It was found that the addition of mango butter significantly inhibited the lipid peroxidation at all concentrations. Based on the results, the authors suggested that mango butter can be used as a suitable natural antioxidant in the food products. Nadeem et al. [12] proposed that the oxidative stability of the butter oil can be improved by blending it with mango butter [12]. Cocoa butter serves as the binding agent of different components in the chocolate and confectionaries. However, the tempering problem and high cost of cocoa butter has led the food industry to search for its alternatives having similar physicochemical properties [4]. Sagiri et al. [14] have reported that mango butter contains the fat profile and other properties similar to cocoa butter and can be explored as an alternative of cocoa butter [14]. Juhurul et al. [6] have reported that mango butter and palm oil blends in 80:20 ratio can be used to produce a high temperature resistant cocoa butter replacer [6].

\section{Conclusion}

Mango is consumed worldwide owing to its sensory pleasures and package of nutrients, but its nutrient rich by-products like the peel and the kernel are wasted by food industries. These by-products have received the attention of the researchers due to their great functional and nutritional potential. The extracted mango butter has been extensively studied for its potential usage in both non-food and food industries. However, further research is still required to discover the efficient methods of extraction and to uncover more applications of mango butter.

\section{Acknowledgment}

The authors would like to acknowledge the funds accredited from the project (INT/Korea/P-37), sanctioned by the Department of Science and Technology (DST), Govt. of India.

\section{References}

1. S Kittiphoom (2012) “Utilization of Mango seed”. Int Food Res J 19(4): 1325-1335.

2. Shah KA, Patel MB, Patel RJ, Parmar PK (2010) "Mangifera indica (mango)". Pharmacogn Rev 4(7): 42-48.

3. Cristian TL, Romeo R, Juan CCE, Serna-Cock L, Belmares-Cerda RE (2016) "Mango seed: Functional and nutritional properties," Trends in Food Science \& Technology 55: 109-117.

4. Nadeem M, Imran M, Khalique A (2016) Promising features of mango (Mangifera indica L.) kernel oil: a review" J Food Sci Technol 53(5): 2185-2195

5. Nagle M, Spreer W, Neidhart S, Sruamsiri P, Carle R, et al. (2005) "Documentation of cavity closure by the seed in mango fruit (Mangifera indica L.)." Deutscher Tropentag 1-5.

6. Jahurul MH, Zaidul IS, Ghafoor K, Al-Juhaimi FY, Nyam KL, et al. (2015) "Mango (Mangifera indica L.) by-products and their valuable components: A review," Food chem183: 173-180.

7. JM Nzikou, A Kimbonguila, L Matos, Loumouamou, NPG Pambou-Tobi, et al. (2010) "Extraction and characteristics of seed kernel oil from mango (Mangifera indica)," Research Journal of Environmental and Earth Sciences 2(1): 31-35.

8. C Rukmini, M Vijayaraghavan (1984) "Nutritional and toxicological evaluation of mango kernel oil," Journal of the American Oil Chemists' Society 61(4): 789-792

9. S Kittiphoom, S Sutasinee (2013) "Mango seed kernel oil and its physicochemical properties," Int Food Res J 20(3): 1145-1149.

10. AM El-Bastawesy et al. (2007) "Grape and mango seeds as untraditional sources of edible oils, antioxidants and antibacterial compounds," in Mansoura Journal of Chemistry, Mansoura Univ Proceedings of the 9th International Mansoura Conf. on Chemistry and its Role in Development pp 17-36.

11. Abdel-Razik MM, Ashoush IS, Nessrien MN, Yassin (2012) "Characteristics of mango seed kernel butter and its effects on quality attributes of muffins," Alex J Fd Sci Technol 9: 1-9.

12. Nadeem M, Imran M, Iqbal Z, Nadeem A, Athar M (2017) “Enhancement of the oxidative stability of butter oil by blending with mango (mangifera indica L.) Kernel oil in ambient and accelerated oxidation," Journal of Food Processing and Prev 41(3): e12957.

13. Jafari J, Gharachorloo M, Hemmaci MH (2014) “The stabilizing effect of three varieties of crude mango seed kernel oil on tallow," Journal of Food Biosciences and Technology 4(1): 31-36.

14. Sagiri SS, Sharma V, Basak P, Pal K (2014) "Mango butter emulsion gels as cocoa butter equivalents: physical, thermal, and mechanical analyses," J Agric Food Chem62(47): 11357-1368. 
This work is licensed under Creative Commons Attribution 4.0 License

DOI: $10.19080 / \mathrm{NFSIJ} .2018 .04 .555641$
Your next submission with Juniper Publishers will reach you the below assets

- Quality Editorial service

- Swift Peer Review

- Reprints availability

- E-prints Service

- Manuscript Podcast for convenient understanding

- Global attainment for your research

- Manuscript accessibility in different formats ( Pdf, E-pub, Full Text, Audio)

- Unceasing customer service

Track the below URL for one-step submission https://juniperpublishers.com/online-submission.php 